\title{
New insights of P2X7 receptor signaling pathway in alveolar functions
}

Amarjit Mishra

\begin{abstract}
Purinergic P2X7 receptor (P2X7R), an ATP-gated cation channel, is unique among all other family members because of its ability to respond to various stimuli and to modulate pro-inflammatory signaling. The activation of P2X7R in immune cells is absolutely required for mature interleukin -1 beta (IL-1beta) and IL-18 production and release. Lung alveoli are lined by the structural alveolar epithelial type I (AEC I) and alveolar epithelial type II cells (AEC II). AEC I plays important roles in alveolar barrier protection and fluid homeostasis whereas AEC II synthesizes and secrete surfactant and prevents alveoli from collapse. Earlier studies indicated that purinergic P2X7 receptors were specifically expressed in AEC I. However, their implication in alveolar functions has not been explored. This paper reviews two important signaling pathways of P2X7 receptors in surfactant homeostatsis and Acute Lung Injury (ALI). Thus, P2X7R resides at the critical nexus of alveolar pathophysiology.
\end{abstract}

\section{Review}

Over the last two decades, a total of 19 different purinergic receptor subtypes (including 7 P2X receptors, 8 $\mathrm{P} 2 \mathrm{Y}$ receptors, and 4 adenosine receptors) that can recognize extracellular ATP and adenosine have been cloned and characterized [1]. In addition, several families of ectonucleotidases that hydrolyse ATP to ADP, AMP and adenosine have been found [2]. These distinct sets of purinergic receptors and ectonucleotidases are expressed on the cell surface of the different mammalian cells and regulate cellular activities through cell-type specific purinergic signaling systems $[3,4]$.

Controlled ATP release from intact cells was first identified in neurons [5]. ATP is also released from non-neuronal cells through vesicular transport [6]. Additional mechanisms for ATP release has been reported including release through stretch-activated channels, voltage-dependent and multi-channel anion transporter or permeases [7], cystic fibrosis transmembrane conductance regulator (CFTR) [8], and P2X7 receptor associated connexin and pannexin hemichannels [9]. ATP release from mouse neutrophil occurs through connexin-43 hemi channels [10].

Extracellular ATP has two fates before being degraded by the ectonucleotidases. The released ATP either acts on

Correspondence: amarjitmisra@gmail.com

National Institute of Health, 10 Center Dr, Bldg No. 10, Bethesda, MD 20892, USA

\section{() Biomed Central

(c) 2013 Mishra; licensee BioMed Central Ltd. This is an Open Access article distributed under the terms of the Creative Commons Attribution License (http://creativecommons.org/licenses/by/2.0), which permits unrestricted use, distribution, and reproduction in any medium, provided the original work is properly cited. the purinoceptors of the same cell (autocrine) or the neighboring cells (paracrine). Autocrine signaling through the purinergic receptors regulates the neutrophil chemotaxis via ATP release from polarized neutrophil in response to chemotactic mediators [11]. The activated T cells also induce the release of ATP through pannexin 1 channels. These hemichannels translocate with P2X receptors to the immune synapse, where they promote $\mathrm{Ca}^{2+}$ influx and cell activation through autocrine purinergic signaling $[12,13]$. The activation of purinergic receptors in immune cells can elicit either positive or negative feedback mechanisms and thus tightly regulate immune responses.

Paracrine purinergic signaling regulates a wide range of physiological process, including immune cell functions $[14,15]$. ATP released from damaged or stressed host cells serves as an important function in the recognition of 'danger signals' and guides phagocytes to inflammatory sites. Thus promotes clearance of damaged and apoptotic cells [16]. In response to damage-associated molecular patterns (DAMPs) and pathogen-associated molecular patterns (PAMPs), activation of inflammasome and the subsequent release of interleukin-1 $\beta$ (IL-1 $\beta$ ) require purinergic singnalling. In the cytoplasm nucleotides are concentrated in the micomolar or even millimolar level, while the extracellular concentration is extremely low, usually in the nanomolar range [17]. ATP is rapidly released upon damage of plasma membrane and diffuses throughout the pericellular space and bind to specific receptors expressed 
by virtually all immune cells [18]. Diffusion of nucleotides is drastically controlled via degradation by ecto-nucleotidases expressed on the plasma membranes of most cells. Rapid metabolism of extracellular ATP generates the antiinflammatory metabolite adenosine and terminates the alert-signal to a checkpoint [19].

\section{$\mathrm{P} 2 \mathrm{X7}$ receptor and inflammation}

P2X7 receptors are expressed primarily on the cells of hematopoietic lineage. The distribution of P2X7 receptor has been studied by permeability and RT-PCR analysis in cultured monocytes/macrophages [20], phagocytes [21], dendritic cells [22], $\mathrm{T}$ lymphocytes [23], B lymphocytes [24], mast cells [25] and eosinophils [26]. P2X7 receptor has also been identified in fibroblasts, endothelial cells and epithelial cells $[27,28]$. Our laboratory has reported previously specific expression of P2X7 receptors in alveolar type I epithelial cells (AEC I) [29].

IL-1 $\beta$ and IL-18 are pro-inflammatory cytokines that requires processing by interleukin converting enzyme (ICE, also known as caspase-1) at specific aspartic residues for mature molecule production. Activation of P2X7 receptor on human macrophages triggers the release of these two cytokines [30-32]. P2X7 receptor is also required for inflammasome assembly and caspase activation [33]. Studies on P2X7 receptor knock-out mice have shown that absence of P2X7 receptor leads to an inability to release IL-1 $\beta$ in response to ATP stimulation from peritoneal macrophages [34]. P2X7 null mice therefore have impaired cytokine signaling cascade in vivo. This suggests that P2X7 receptor activation provides signals for maturation and release of IL-1 $\beta$ and initiation of a cytokine cascade.

The unprocessed and mature form of IL- $1 \beta$ was found in the shed microvesicles [35]. P2X7-mediated microvesicle formation and shedding might be a crucial pathway for secretory protein release from cytoplasm. L-selectin (CD62L; a C-type lectin) and CD23 (low affinity IgE receptor) are involved in the adhesive interaction and rolling behavior of lymphocytes on endothelial cells [36]. P2X7 receptor contributes to the regulation of intercellular interactions and to the generation of soluble markers.Elevated levels of CD62L and CD23 in sera have been reported from B-cell chronic lymphocytic leukaemia (B-CLL) patients [37]. ATP-induced L-selectins and CD23 shedding have also been shown to decrease in P2X7 receptor knock-out mice, indicating the pathophysiological role of P2X7 receptor [38]. Involvement of P2X7 receptor in ATP-induced apoptosis is well documented in lymphocytes, monocytes, macrophages, murine thymocytes, and dendritic cells $[39,40]$. P2X7 receptor activation has been shown to stimulate the activity of intracellular caspases prior to ATP-induced apoptosis. $\mathrm{K}^{+}$efflux through the P2X7 receptor ion channel leads to cell shrinkage and activation of caspase cascades [41].
P2X7 receptor and regulation of lung surfactant secretion Lung surfactant is a lipid-enriched substance comprising of $80 \%$ glycerophospholipids, $10 \%$ cholestrol and about $5-10 \%$ proteins. Di-palmitoylphosphatidyl choline (DPPC) is the major glycerophospholipid present in surfactant. The major function of surfactant is to reduce surface tension in the lung. There are 4 major surfactant proteins. SP-B and SP-C are synthesized in endoplasmic reticulumn and further processed by Golgi apparatus. These proteins are stored in lamellar bodies preceeding exocytosis [42]. However, SP-A and SP-D secretes constitutively independent of lamellar bodies [43]. Alveolar epithelial type II cells (AEC II) stores and secrete surfactant. Physiologically, mechanical stretch, labor, and ventilation induce surfactant secretion from AEC II. However, recent experiments suggests that lung distensions rather than systemic changes accompanying hyperventilation $\left(\mathrm{PCO}_{2}, \mathrm{Po}_{2}\right.$, and $\left.\mathrm{pH}\right)$ increases surfactant secretion [44]. The mechanical stretch of the AEC II during an enhanced inspiration ('sigh') is a direct stimulus for surfactant secretion.

The commonly held view of regulated surfactant secretion from AEC II involves cell membrane receptors including $\beta_{2}$-adrenergic, adenosine $\mathrm{A} 2 \mathrm{~B}$, and purinergic P2Y2. ATP, UTP, adenosine, platelet activating factor, LPS, and IL-1 $\beta$ are the known agonists to stimulate surfactant secretion [45]. Stimulation of these receptors ultimately leads to activation of protein kinase A (PKA), protein kinase $\mathrm{C}$ (PKC) and calcium and calmodulin kinase (CaMK) and their downstream partners. The purinergic metabotropic receptor, P2Y2, is coupled to the G protein Gq, which stimulates phospholipase C (PLC) and hydrolyzes phosphotidylinositol biphosphate into diacylglycerol (DAG) and inositol triphosphate $\left(\mathrm{IP}_{3}\right)$ [46]. The increase in intracellular $\mathrm{Ca}^{2+}$ concentration results in enhanced surfactant secretion $[47,48]$. Surfactant exocytosis in AEC II is extremely sensitive to perturbations of $\mathrm{Ca}^{2+}$. In vitro, secretagogues including $\beta_{2}$-adrenergic agonists (terbutaline), $A_{2 B}$ receptor agonists (adenosine), $\mathrm{P}_{2} \mathrm{Y}_{2}$ receptor agonists (ATP and UTP), PKC activators (phorbol esters) and calcium ionophores (A23187) have been shown to stimulate surfactant exocytosis. Terbutaline and adenosine activate adenyl cyclase which further stimulates PKA-mediated signaling. Moreover, ATP and phorbol esters activate PKC and downstream signaling molecules. The ionophores increase the intracellular calcium concentrations which further activates PKC and CAMK II. Activation of various kinases leads to phosphorylation of various proteins resulting in surfactant exocytosis. However, the mechanism of how the phosphorylation induces secretion is incompletely understood.

\section{Contribution of $\mathrm{AEC} I$ and $\mathrm{P} 2 \mathrm{X7}$ receptor signaling in surfactant secretion}

The alveolar epithelium has two specialized epithelial cell types: the terminally differentiated squamous AEC I and 
the surfactant producing cuboidal AEC II. The AEC I cover $95 \%$ of the alveolar surface and form a tight epithelial barrier with the AEC II to facilitate gas and water exchange. Alveolar epithelial cells are closely associated with endothelial cells, stromal fibroblasts, inflammatory cells, and the accompanying extracellular matrix. The function of AEC I has been relatively unexplored because it has been extremely difficult to isolate and culture viable AEC I [49]. Our lab and other labs have developed methods to isolate AEC I [50].

AEC I respond to the forces generated by mechanical ventilation i.e. conversion of physical forces on the cell membranes and/or receptors into activation of intracellular signaling pathway leading to $\mathrm{Ca}^{2+}$ wave generation. The intracellular $\mathrm{Ca}^{2+}$ contributes to integrate signaling in lung epithelium. The mechanisms underlying the coordination of intracellular $\mathrm{Ca}^{2+}$ changes in AEC I to neighboring AEC II involve diffusion of ions/second messenger molecules through gap junctions and release of ATP or UTP in the extracellular spaces. This subsequently activates $\mathrm{Ca}^{2+}$ signaling pathways in AEC II through purinergic receptors and induces surfactant release. Recent studies using the in situ technique confirm that calcium waves passed from AEC I to AEC II result in the release of surfactant from AEC II [51]. Mechanical stimulation of AEC I-like cells in heterocellular culture propagated calcium to neighboring AEC II-like cells mainly via an apyrase-sensitive mechanism, suggesting that ATP is an extracellular mediator of alveolar cell communications [52]. ATP is produced by AEC I in response to mechanical stimulation and in turn triggers surfactant secretion from AEC II [53]. However, the mechanism of ATP release from AEC I has not been established.

P2X7 receptors are specifically expressed in AEC I [29]. The expression of P2X7 receptor couples caveolin-1 as Cav-1 knock-out mice shows reduced P2X7 receptor immunoreactivity in lung [54]. Previously, we have shown that the stimulation of P2X7 receptor in AEC I releases soluble mediator, ATP, which acts in a paracrine fashion on AEC II. Activation of P2Y2 receptors by extracellular ATP increases surfactant secretion from AEC II via a PKCdependent signaling pathway. Moreover, the paracrine regulation of surfactant exocytosis by $\mathrm{P} 2 \mathrm{X} 7$ receptor is a physiologically relevant phenomenon as the P2X7 receptor knock-out mice are less responsive to hyperventilationinduced surfactant release [55]. Therefore, P2X7 receptors in AEC I are an important regulator of surfactant secretion and AEC I and AEC II communications.

\section{Acute lung injury}

Acute Respiratory Disease Syndrome (ARDS) is acute lung injury (ALI) of the alveolar/capillary membrane. ARDS is characterized by permeability pulmonary edema (fluid in the alveolar space) and acute respiratory failure. It is defined as acute respiratory distress with diffuse alveolar infiltrates on chest X-ray, severe hypoxemia $\left(\mathrm{PaO}_{2} / \mathrm{F}_{\mathrm{I}} \mathrm{O}_{2}<200\right)$. The etiology of ARDS includes aspiration of gastric contents, pneumonia, smoke inhalation, sepsis, trauma, and drug overdose, multiple transfusions, pancreatitis, and venous air embolism. Sepsis is an important predisposing factor, present in $40 \%$ of ARDS patients. Multiple risk factors increase the chance of developing ARDS. ALI is a common complication of mechanical ventilated patients and often synergized the upshots with sepsis background. Mechanical ventilation augments the acute lung injury caused by bacterial products.

Alveolar cells produce a range of proinflammatory cytokines when exposed to bacterial products. Importantly, ATP is a potent candidate to activate the innate immune response. There is a significant degree of purinergic interplay in the prognosis of the ALI pathogenecity. The pathogenesis of the disease can be inferred by concentering on the factors that are responsible for the accumulation of protein-rich and neutrophillic pulmonary edema in the lung and, the mechanisms that impair the removal of pulmonary edema fluid [56]. Inflammatory cells from the lung are the inciting factors in the pathogenesis of ALI. The protein -rich edema fluid in ALI is associated with large numbers of neutrophils, denuded alveolar epithelial cells and proinflammatory markers including cytokines, oxidants procoagulant factors and proteases [57] .

The initial cause of ALI is the lung vascular injury. An increase in lung vascular permeability occurs primarily at the level of lung microcirculation, which in turn results in the accumulation of protein-rich pulmonary edema fluid, even in the presence of normal lung vascular pressur [58]. A sustained loss of normal endothelial barrier function is best described in neutrophil-dependent lung injury [59]. Neutrophil sequestration and activation in the lung microvasculature leads to degranulation and release of several toxic mediators, including ROS, proinflammatory cytokines and procoagulant molecules, resulting in increase of vascular permeability.

Alveolar epithelial injury is another cardinal characteristic of ALI. Although the mechanisms responsible for epithelial injury in ALI are poorly understood, it appears that neutrophil and their products are primarily responsible for the increased paracellular alveolar permeability in ALI. However, neutrophil can cross the alveolar epithelium without affecting the lung epithelial permeability $[57,60]$. In pathological states the migration of a large number of neutrophils results in increased epithelial injury [56]. Furthermore, the degree of neutrophil activation (priming) by exposure to chemokines and other proinflammatory cytokines seems to play a crucial role in the alveolar epithelial injury as neutrophils crawl into the distal airspaces. Transepithelial migration of neutrophils into the distal airspaces involves three distinct and sequential steps of adhesion, migration and 


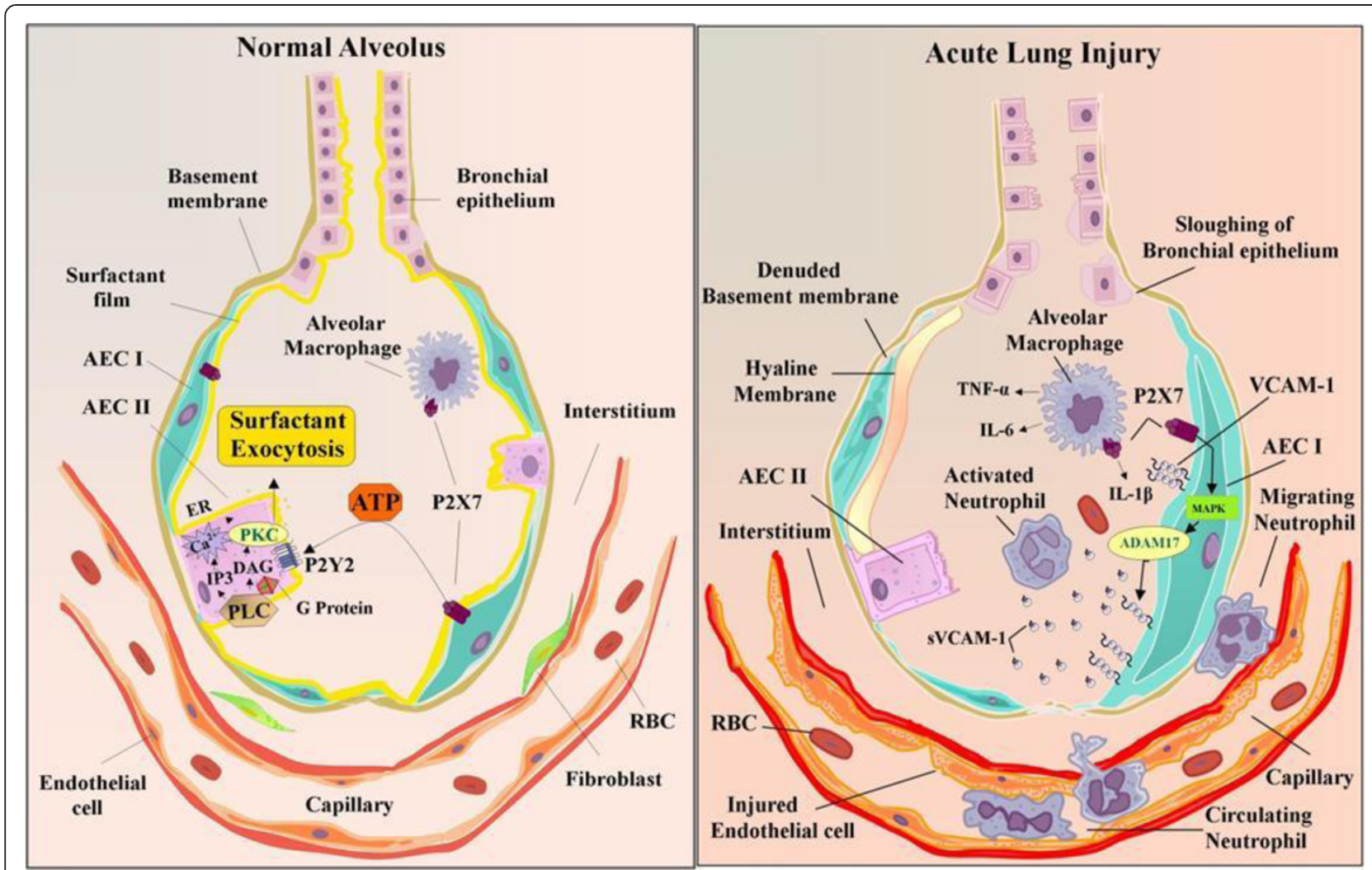

Figure 1 Proposed pathophysiological role of P2X7 receptor signaling in the normal and injured alveolus.

post-migration. Neutrophils adhere to the basolateral epithelial surface by $\beta 2$-integrins $[61,62]$. The initial adhesion of neutrophils to the basolateral surface is primarily mediated by CD11b/CD18 molecules [63]. However, CD18independent transmigration of neutrophils has also been documented. The paracellular route of neutrophil migration to the distal airspaces is also associated with CD47, a cell-surface molecule expressed on epithelial cells and neutrophils [64]. Once they traverse the epithelium and enter the airspaces, neutrophils adhere to the apical surface, where they phagocytize and kill bacteria. The release of toxic intracellular molecules from activated neutrophils induces dissolution of tight junction and necrosis of AEC I. Finally, apoptosis and phagocytosis of inflammatory cells are critical for the resolution of inflammation and mitigation of lung tissue damage.

\section{$\mathrm{P} 2 \mathrm{X7}$ receptor signaling in acute lung injury}

P2X7 receptor knock-out mice are less susceptible to smoke-induced lung inflammation and emphysema. P2X7 receptor expressions increased rapidly in alveolar macrophages, circulating neutrophils and in whole lung tissue following smoke-induced lung inflammation and are blocked by selective intra-pulmonary P2X7 receptor inhibition [65]. Furthermore, P2X7 receptor knock-out mice shows reduced inflammation and lung fibrosis to airway- administered bleomycin. In the presence of ATP $\gamma \mathrm{S}$, a stable P2X7 receptor agonist, lung cell recruitment and matrix remodeling proteins such as matrixmetalloproteinase-9 (MMP-9) and tissue-inhibitor of metalloproteinase (TIMP-1) were increased rapidly. Therefore, P2X7 receptor plays an important pro-inflammatory function in injured alveolus. Delving into the mechanism mediated by $\mathrm{P} 2 \mathrm{X} 7$ receptor in injury, we found that $\mathrm{P} 2 \mathrm{X} 7$ receptors are involved in soluble Vascular Cell Adhesion Molecule-1 (sVCAM-1) release from AEC I (Unpublished data). sVCAM-1 resembles an important regulatory component of the inflammatory response and is detectable in serum and other body fluids. sVCAM-1 level is elevated in alveolar lining fluid from pneumonia and asthma patients [66,67]. Moreover, our data suggest the metalloprotease, ADAM17 are responsible for VCAM-1 shedding from AEC I surface in a P2X7 receptor-dependent manner. This P2X7 receptor mediated shedding of VCAM-1 from AEC I is crucial for the recruitment of neutrophils in the alveolar space.

\section{Conclusions}

P2X7 receptor plays important roles in immunity, inflammation, bone homeostasis, neurological function and neoplasia. There is increase body of evidence implicating P2X7 receptor in various pathological conditions of pulmonary, cardiac, renal, skeletal muscle and central nervous system 
(CNS) disorders, where inflammation is the corner stone of these disorders.

The involvement of $\mathrm{P} 2 \mathrm{X} 7$ receptor in the pathogenesis of pulmonary emphysema [68], and COPD [69] has been well documented. Pulmonary fibrosis is characterized by inflammation and fibrosis of the interstitium and destruction of alveolar histoarchitecture. Recent animal studies have identified the importance of $\mathrm{P} 2 \mathrm{X} 7$ receptor and pannexin-1 complex in IL-1 $\beta$ maturation, inflammation and evolution to pulmonary fibrosis [70].

AEC I play important roles in alveolar barrier protection and fluid homeostasis. Earlier studies indicated that purinergic P2X7 receptors were specifically expressed in AEC I. Although P2X7 receptor-mediated critical signaling pathways in immune cells have been identified, less is known about their functions in alveolar pathophysiology. Several line of evidence suggests that the pro-inflammatory P2X7 receptor signaling are druggable targets in lung inflammatory diseases. However, the mechanism of P2X7 receptor-mediated signaling pathways in alveolus in particular AEC I are not well understood.

Finally, we propose the following models for P2X7 receptor signaling in alveolus (Figure 1). (A) In the normal alveolus, activation of P2X7 receptor in AEC I cell surface leads to ATP release. ATP in the extracellular space activates neighboring AEC II and stimulates surfactant secretion through P2Y2 receptor signaling pathway. (B) In the injured lung, there is sloughing of both bronchial and alveolar epithelial cells, denuded alveolar basement membrane. Alveolar macrophages secrete cytokines; IL-1 1 , IL-6, and TNF- $\alpha$, that act locally on AEC I. This increases the VCAM-1 expression in AEC I membrane. P2X7 receptor stimulation on AEC I modulate ADAM17 activity through MAPK activation. ADAM17 shed VCAM-1 from the AEC I surface. sVCAM-1 in the alveolar space stimulate neutrophil chemotaxis and sequestrations. Thus, P2X7R resides at the critical nexus of surfactant regulation, cytokine modulation, neutrophil recruitment and inflammation in lung.

\section{Competing interests}

The author has no conflicts of interest to declare.

\section{Acknowledgements}

This work was partly supported by Center for Veterinary Health Sciences, Oklahoma State University, Stillwater, USA.

Received: 1 March 2013 Accepted: 29 April 2013

Published: 1 May 2013

\section{References}

1. Ralevic V, Burnstock G: Receptors for purines and pyrimidines. Pharmacol Rev 1998, 50:413-492.

2. Zimmermann H: Extracellular metabolism of ATP and other nucleotides. Naunyn-Schmiedebergs Archives of Pharmacology 2000, 362:299-309.

3. Burnstock $\mathrm{G}$ : Unresolved issues and controversies in purinergic signalling. J Physiology-London 2008, 586:3307-3312.

4. Corriden R, Insel PA: Basal Release of ATP: An Autocrine-Paracrine Mechanism for Cell Regulation. Sci Signal 2010, 3(104):re1.
5. Abbracchio MP, Burnstock G, Verkhratsky A, Zimmermann H: Purinergic signalling in the nervous system: an overview. Trends Neurosci 2009, 32:19-29.

6. Praetorius HA, Leipziger J: ATP release from non-excitable cells. Purinergic Signalling 2009, 5:433-446.

7. Alawqati Q: Regulation of Ion Channels by Abc Transporters That Secrete Atp. Science 1995, 269:805-806.

8. Braunstein GM, et al: Cystic fibrosis transmembrane conductance regulator facilitates ATP release by stimulating a separate ATP release channel for autocrine control of cell volume regulation. J Biol Chem 2001, 276:6621-6630.

9. Eltzschig HK, et al: ATP release from activated neutrophils occurs via connexin 43 and modulates adenosine-dependent endothelial cell function. Circ Res 2006, 99:1100-1108.

10. Chen $Y$, et al: ATP release guides neutrophil chemotaxis via P2Y2 and A3 receptors. Science 2006, 314:1792-1795.

11. Schenk U, et al: Purinergic Control of T Cell Activation by ATP Released Through Pannexin-1 Hemichannels. Sci Signal 2008, 1(39):ra6.

12. Yip $L$, et al: Autocrine regulation of T-cell activation by ATP release and P2X(7) receptors. FASEB J 2009, 23:1685-1693.

13. Bours M, Swennen E, Di Virgilio F, Cronstein B, Dagnelie P: Adenosine 5 '-triphosphate and adenosine as endogenous signaling molecules in immunity and inflammation. Pharmacol Ther 2006, 112:358-404.

14. Elliott MR, et al: Nucleotides released by apoptotic cells act as a find-me signal to promote phagocytic clearance. Nature 2009, 461:282-U165.

15. Dubyak GR: Focus on "Extracellular ATP signaling and P2X nucleotide receptors in monolayers of primary human vascular endothelial cells". Am J Physiol Cell Physiol 2002, 282:C242-C244.

16. Di Virgilio F, et al: Nucleotide receptors: an emerging family of regulatory molecules in blood cells. Blood 2001, 97:587-600.

17. Ohta A, Sitkovsky M: Role of G-protein-coupled adenosine receptors in downregulation of inflammation and protection from tissue damage. Nature 2001, 414:916-920.

18. Hickman SE, Elkhoury J, Greenberg S, Schieren I, Silverstein SC: P2Z Adenosine-Triphosphate Receptor Activity in Cultured Human Monocyte-Derived Macrophages. Blood 1994, 84:2452-2456.

19. Coutinho Silva R, Alves LA, de Carvalho ACC, Savino W, Persechini PM: Characterization of $\mathrm{P}-2 \mathrm{Z}$ purinergic receptors on phagocytic cells of the thymic reticulum in culture. Biochimica et Biophysica Acta-Biomembranes 1996, 1280:217-222.

20. Coutinho-Silva $\mathrm{R}$, et al: $\mathrm{P}-2 \mathrm{Z} / \mathrm{P} 2 \mathrm{X}(7)$ receptor-dependent apoptosis of dendritic cells. Am J Physiol Cell Physiol 1999, 276:C1139-C1147.

21. Baricordi OR, et al: An ATP-activated channel is involved in mitogenic stimulation of human T lymphocytes. Blood 1996, 87:682-690.

22. Wiley JS, Chen R, Wiley MJ, Jamieson GP: The Atp4- Receptor-Operated Ion Channel of Human-Lymphocytes - Inhibition of Ion Fluxes by Amiloride Analogs and by Extracellular-Sodium lons. Arch Biochem Biophys 1992, 292:411-418

23. Tatham PER, Lindau M: Atp-Induced Pore Formation in the PlasmaMembrane of Rat Peritoneal Mast-Cells. J Gen Physiol 1990, 95:459-476.

24. Ferrari $D$, et al: $P 2$ purinergic receptors of human eosinophils: characterization and coupling to oxygen radical production. FEBS Lett 2000, 486:217-224.

25. Ferrari $D$, et al: Mouse microglial cells express a plasma membrane pore gated by extracellular ATP. J Immunol 1996, 156:1531-1539.

26. Solini $A$, et al: High glucose modulates $P 2 X(7)$ receptor-mediated function in human primary fibroblasts. Diabetologia 2000, 43:1248-1256.

27. Ray FR, Huang W, Slater M, Barden JA: Purinergic receptor distribution in endothelial cells in blood vessels: a basis for selection of coronary artery grafts. Atherosclerosis 2002, 162:55-61.

28. Slater M, Barden JA, Murphy CR: Distributional changes of purinergic receptor subtypes $(\mathrm{P} 2 \mathrm{X}(1-7))$ in uterine epithelial cells during early pregnancy. Histochem J 2000, 32:365-372

29. Chen $Z M$, et al: Identification of two novel markers for alveolar epithelia type I and II cells. Biochem Biophys Res Commun 2004, 319:774-780.

30. Chakfe $Y$, et al: ADP and AMP induce interleukin-1 beta release from microglial cells through activation of ATP-primed P2X(7) receptor channels. J Neurosci 2002, 22:3061-3069.

31. Ferrari $D$, et al: Extracellular ATP triggers IL-1 beta release by activating the purinergic P2Z receptor of human macrophages. J Immunol 1997, 159:1451-1458. 
32. Perregaux DG, McNiff $P$, Laliberte $R$, Conklyn $M$, Gabel CA: ATP acts as an agonist to promote stimulus-induced secretion of IL-1 beta and IL-18 in human blood. J Immunol 2000, 165:4615-4623.

33. Mehta VB, Hart J, Wewers MD: ATP-stimulated release of interleukin (IL)-1 beta and IL-18 requires priming by lipopolysaccharide and is independent of caspase-1 cleavage. J Biol Chem 2001, 276:3820-3826.

34. Solle $M$, et al: Altered cytokine production in mice lacking $P 2 X(7)$ receptors. J Biol Chem 2001, 276:125-132.

35. MacKenzie A, et al: Rapid secretion of interleukin-1 beta by microvesicle shedding. Immunity 2001, 15:825-835.

36. Gu B, Bendall $L$, Wiley JS: Adenosine triphosphate-induced shedding of CD23 and L-selectin (CD62L) from lymphocytes is mediated by the same receptor but different metalloproteases. Blood 1998, 92:946-951.

37. Wiley JS, et al: A loss-of-function polymorphic mutation in the cytolytic P2X7 receptor gene and chronic lymphocytic leukaemia: a molecular study. Lancet 2002, 359:1114-1119.

38. Jamieson GP, Snook MB, Thurlow PJ, Wiley JS: Extracellular ATP causes loss of L-selectin from human lymphocytes via occupancy of $P(2) Z$ purinoceptors. J Cell Physiol 1996, 166:637-642.

39. Blanchard DK, Mcmillen S, Djeu JY: IFN-Gamma Enhances Sensitivity of Human Macrophages to Extracellular Atp-Mediated Lysis. J Immunol 1991, 147:2579-2585

40. Pizzo P, et al: Role of $\mathrm{P}(2 \mathrm{Z})$ Purinergic Receptors in Atp-Mediated Killing of Tumor-Necrosis-Factor (Tnf)-Sensitive and Tnf-Resistant L929 Fibroblasts. J Immunol 1992, 149:3372-3378.

41. Bortner CD, Hughes FM, Cidlowski JA: A primary role for $\mathrm{K}+$ and $\mathrm{Na}+$ efflux in the activation of apoptosis. J Biol Chem 1997, 272:32436-32442.

42. Clark JC, et al: Targeted Disruption of the Surfactant Protein-B Gene Disrupts Surfactant Homeostasis. Causing Respiratory-Failure in Newborn Mice. Proc Natl Acad Sci USA 1995, 92:7794-7798.

43. Rooney SA: Regulation of surfactant secretion. Comp Biochem Physiol A Mol Integr Physiol 2001, 129:233-243.

44. Tschumperlin DJ, Margulies SS: Alveolar epithelial surface area-volume relationship in isolated rat lungs (vol 86, pg 2026, 1999). J Appl Physiol 1999, 87:U34.

45. Andreeva AV, Kutuzov MA, Voyno-Yasenetskaya TA: Regulation of surfactant secretion in alveolar type II cells. Am J Physiol Lung Cell Mol Physiol 2007, 293:L259-L271.

46. Rooney SA, Gobran LI, Griese M: Signal-Transduction Mechanisms of Atp Stimulated Surfactant Phosphatidylcholine (Pc) Secretion in Rat Type-li Pneumocytes. FASEB J 1992, 6:A365.

47. Ashino $Y$, Ying $X Y$, Dobbs LG, Bhattacharya J: [Ca2+](i) oscillations regulate type II cell exocytosis in the pulmonary alveolus. Am J Physiol Lung Cell Mol Physiol 2000, 279:L5-L13.

48. Williams MC: Alveolar type I cells: Molecular phenotype and development. Annu Rev Physiol 2003, 65:669-695.

49. Wang SH, Hubmayr RD: Type I Alveolar Epithelial Phenotype in Primary Culture. Am J Respir Cell Mol Biol 2011, 44:692-699.

50. Chen JW, Chen ZM, Narasaraju T, Jin N, Liu L: Isolation of highly pure alveolar epithelial type I and type II cells from rat lungs (vol 84, pg 727, 2004). Lab Invest 2005, 85:1181.

51. Boitano S, Isakson BE, Seedorf GJ, Lubman RL: Functional coupling and cell signaling between alveolar type I and type II epithelial cells. FASEB J 2004, 18:A1051.

52. Isakson BE, Seedorf GJ, Lubman RL, Evans WH, Boitano S: Cell-cell communication in heterocellular cultures of alveolar epithelial cells. Am J Respir Cell Mol Biol 2003, 29:552-561.

53. Patel AS, et al: Paracrine stimulation of surfactant secretion by extracellular ATP in response to mechanical deformation. Am J Physiol Lung Cell Mol Physiol 2005, 289:L489-L496.

54. Barth $K$, et al: Caveolin-1 influences $P 2 X(7)$ receptor expression and localization in mouse lung alveolar epithelial cells. FEBS J 2007, 274:3021-3033.

55. Mishra A, Chintagari NR, Guo Y, Weng T, Su L, Liu L: Purinergic P2X receptor regulates lung surfactant secretion in a paracrine manner. $J$ Cell Sci 2011, 124(4):657-668.

56. Downey GP, Worthen GS, Henson PM, Hyde DM: Neutrophil Sequestration and Migration in Localized Pulmonary Inflammation - Capillary Localization and Migration Across the Interalveolar Septum. Am Rev Respir Dis 1993, 147:168-176

57. Martin TR, Pistorese BP, Chi EY, Goodman RB, Matthay MA: Effects of Leukotriene-B4 in the Human-Lung - Recruitment of Neutrophils Into the Alveolar Spaces Without A Change in Protein Permeability. J Clin Invest 1989, 84:1609-1619.

58. Brigham KL, Staub NC: Pulmonary edema and acute lung injury research. Am J Respir Crit Care Med 1998, 157:S109-S113.

59. Matthay MA, Zimmerman GA: Acute lung injury and the acute respiratory distress syndrome - Four decades of inquiry into pathogenesis and rational management. Am J Respir Cell Mol Biol 2005, 33:319-327.

60. Wienerkronish JP, Albertine KH, Matthay MA: Differential Responses of the Endothelial and Epithelial Barriers of the Lung in Sheep to Escherichia-Coli Endotoxin. J Clin Invest 1991, 88:864-875.

61. Folkesson HG, Matthay MA: Inhibition of CD18 or CD11b attenuates acute lung injury after acid instillation in rabbits. J App/ Physio/ 1997, 82:1743-1750.

62. Gao XP, et al: Differential role of CD18 integrins in mediating lung neutrophil sequestration and increased microvascular permeability induced by Escherichia coli in mice. J Immunol 2001, 167:2895-2901.

63. Parkos CA, Delp C, Arnaout MA, Madara JL: Neutrophil Migration Across A Cultured Intestinal Epithelium - Dependence on A Cd11B Cd18Mediated Event and Enhanced Efficiency in Physiological Direction. J Clin Invest 1991, 88:1605-1612.

64. Su X, Johansen M, Looney MR, Brown EJ, Matthay MA: CD47 deficiency protects mice from lipopolysaccharide-induced acute lung injury and Escherichia coli pneumonia. J Immunol 2008, 180:6947-6953.

65. Lucattelli M, et al: P2X(7) Receptor Signaling in the Pathogenesis of Smoke-Induced Lung Inflammation and Emphysema. Am J Respir Cell Mol Biol 2011, 44:423-429.

66. Janson $\mathrm{C}$, et al: Circulating adhesion molecules in allergic and nonallergic asthma. Respir Med 2005, 99:45-51.

67. Matsuno $\mathrm{O}$, et al: Elevated soluble ADAM8 in bronchoalveolar lavage fluid in patients with eosinophilic pneumonia. Int Arch Allergy Immunol 2007, 142:285-290

68. Eltom S, et al: P2X7 Receptor and Caspase 1 Activation Are Central to Airway Inflammation Observed after Exposure to Tobacco Smoke. PLoS One 2011, 6(9):e24097.

69. Cicko S, et al: Purinergic Receptor Inhibition Prevents the Development of Smoke-Induced Lung Injury and Emphysema. J Immunol 2010, 185:688-697.

70. Riteau N, et al: Extracellular ATP Is a Danger Signal Activating P2X(7) Receptor in Lung Inflammation and Fibrosis. Am J Respir Crit Care Med 2010, 182:774-783.

doi:10.1186/1423-0127-20-26

Cite this article as: Mishra: New insights of P2X7 receptor signaling pathway in alveolar functions. Journal of Biomedical Science 2013 20:26.

\section{Submit your next manuscript to BioMed Central and take full advantage of:}

- Convenient online submission

- Thorough peer review

- No space constraints or color figure charges

- Immediate publication on acceptance

- Inclusion in PubMed, CAS, Scopus and Google Scholar

- Research which is freely available for redistribution 